\title{
Soybean Oil Enriched with Antioxidants Extracted from Watermelon (Citrullus colocynthis) Skin Sap and Coated in Hydrogel Beads via Ionotropic Gelation
}

\author{
Muhammad Farooq ${ }^{1,+}{ }^{D}$, Elham Azadfar ${ }^{2,+}$, Monica Trif ${ }^{3, *} \mathbb{D}$, Ramezan Ali Jabaleh ${ }^{4}$, Alexandru Rusu $5, * \mathbb{D}$, \\ Zohre Bahrami ${ }^{6}$, Mahniya Sharifi ${ }^{6}$, Sneh Punia Bangar ${ }^{7}$ D, Naila Ilyas ${ }^{8}$ D, Bianca Eugenia Stefănescu ${ }^{5}$ and \\ Yunyang Wang ${ }^{1, *}$
}

check for

updates

Citation: Farooq, M.; Azadfar, E.; Trif, M.; Jabaleh, R.A.; Rusu, A.; Bahrami, Z.; Sharifi, M.; Bangar, S.P.; Ilyas, N.; Ștefănescu, B.E.; et al. Soybean Oil Enriched with Antioxidants Extracted from Watermelon (Citrullus colocynthis) Skin Sap and Coated in Hydrogel Beads via Ionotropic Gelation. Coatings 2021, 11, 1370. https:// doi.org/10.3390/coatings11111370

\section{Academic Editors: Fengwei}

(David) Xie and

Alexandra Muñoz-Bonilla

Received: 1 October 2021

Accepted: 30 October 2021

Published: 8 November 2021

Publisher's Note: MDPI stays neutral with regard to jurisdictional claims in published maps and institutional affiliations.

Copyright: (c) 2021 by the authors. Licensee MDPI, Basel, Switzerland. This article is an open access article distributed under the terms and conditions of the Creative Commons Attribution (CC BY) license (https:/ / creativecommons.org/licenses/by/ $4.0 /)$
1 College of Food Science and Engineering, Northwest A\&F University, Xianyang 712100, China; farooq.fst28@gmail.com

2 Young Researchers and Elites Club, Sabzevar Branch, Islamic Azad University, Sabzevar 9618735133, Iran; elham_az313@yahoo.com

3 Centre for Innovative Process Engineering (CENTIV) GmbH, 28857 Syke, Germany

4 School of Health, Kerman University of Medical Sciences, Kerman 7616913439, Iran; Jabaleh61@yahoo.com

5 Life Science Institute, University of Agricultural Sciences and Veterinary Medicine Cluj-Napoca, 400372 Cluj-Napoca, Romania; biancavodnar@yahoo.com

6 Department of Food Chemistry, Sabzevar Branch, Islamic Azad University, Sabzevar 9618814711, Iran; Zohrehbahrami_2012@yahoo.com (Z.B.); mah68sharif@gmail.com (M.S.)

7 Department of Food, Nutrition and Packaging Sciences, Clemson University, Clemson, SC 29634, USA; snehpunia69@gmail.com

8 Graduate School of Chinese Academy of Agricultural Sciences, Beijing 100081, China; 2019y90100028@caas.cn

* Correspondence: monica_trif@hotmail.com (M.T.); rusu_alexandru@hotmail.com (A.R.); wyy10421@163.com (Y.W.)

+ Co-first author, these authors contributed equally to this work.

Abstract: Many plants and fruits are rich in antioxidant and antimicrobial compounds, such as phenolic compounds. Watermelon is one example, as various parts of the fruit present interesting phytochemical profiles. This study demonstrates that a natural C. colocynthis (watermelon) (W) skin sap (SS) extract can effectively improve the oxidative stability of microencapsulated soybean (SB) oil. By employing a combination of alginate-xanthan gums (AXG) in a matrix hydrogel bead model with WSS extract, high encapsulation efficiency can be obtained (86\%). The effects of process variables on the ultrasound-assisted extraction (UAE) of phenolic compounds from watermelon (W) skin sap (SS) using the response surface methodology (RSM), as an optimized and efficient extraction process, are compared with the effects of a conventional extraction method, namely the percolation method. The WSS extracts are obtained via UAE and RSM or the conventional percolation extraction method. The two obtained extracts and synthetic antioxidant butylated hydroxytolune (BHT) are added to SB oil separately and their antioxidant effects are tested and compared. The results show the improved oxidative stability of SB oil containing the extract obtained via the optimized method (20-30\%) compared to the SB oil samples containing extract obtained via the percolation extraction method, synthetic antioxidant (BHT), and SB oil only as the control (no antioxidant added). According to existing studies, we assume that the use of WSS as an effective antioxidant will ensure the prolonged stability of encapsulated SB oil in hydrogel beads, as it is well known that extended storage under different conditions may lead to severe lipid oxidation.

Keywords: soybean oil; skin sap; ultrasound-assisted extraction; response surface; stability; phenolic compound; encapsulation; gum

\section{Introduction}

In the 2020-2021 crop year, soybean (SB) oil was the most produced type of oilseed globally; worldwide, around 362 million metric tons of soybeans were produced [1]. The 
oxidation reactions are the important factor involved in oil and fat spoilage, because these reactions cause unwanted changes in the flavor, color, and texture of fat- and oil-containing products [2,3].

The speed of the reaction depends on the fatty acid pattern of the oil (rapeseed oil > peanut oil $>$ soybean oil, linseed oil, safflower oil), which increases with the number of double bonds (stearic acid $<$ oleic acid $<$ linoleic acid $<$ linolenic acid $<$ arachidonic acid $<$ pentanoic and hexane fatty acids) [4-6]. Saturated and trans-unsaturated fatty acids oxidize more slowly than cis-unsaturated acids. Unsaturated fatty acids can be oxidized spontaneously by atmospheric oxygen at room temperature or at moderately elevated temperatures. The rate of reaction increases with the number of double bonds in the fat molecule. Soybean contains highly palmitate, stearic, oleic, linoleic, and linoleic fatty acids, which increases the oxidation risk $[7,8]$.

These changes are because of the free radicals produced during the oxidation process. In addition, autooxidation of polyunsaturated fatty acids not only reduces the nutritional value of soybean oil but also may lead to colds, heart disease, cancer, and the mutagenicity of other important diseases in living organisms [9].

Through recent advances in genetic modification, a soybean seed containing $83 \%$ oleic acid (rather than containing unsaturated linolenic acid as the major constituent) has been developed. This new seed provides oils that show about 30 times the oxidative stability and viscosity stability of conventional oil. Antioxidants still remain one of the most efficient and cost-effective ways to control the development of oxidative rancidity and to improve the oxidative stability of oils. Antioxidants from natural sources have been used for centuries [10].

Antioxidants are divided into two major categories: natural and synthetic. The consumption of synthetic antioxidants has adverse effects on human health. Some of them have been removed from lists of appropriate additives. The most frequent synthetic types are butylated hydroxyl anisole (BHA), butylated hydroxyl toluene (BHT), propyl gallate (PG), and tert-butyl hydroquinone (TBHQ). Replacing synthetic antioxidants with natural antioxidants, especially from sustainable sources, is of great interest nowadays [11]. The sustainable sources of natural antioxidants include plant phenolic compounds, which can be found in all parts of plants. The results from various studies have indicated that the antioxidant activity levels of some fruits and vegetables widely depend on the total content of phenolic compounds [12,13]. A natural antioxidant must be more effective and economical in order to replace a synthetic one.

Watermelon Abu Jahl or Hanzal (Citrullus colocynthis) belongs to the watermelon family, although it differs from ordinary watermelon in that it has a smaller size and a firmer body. Its skin is a rich source of natural antioxidants, containing abundant amounts of cucurbitacin, lycopenes, citrulline, and various polyphenols. Its skin tastes spicy and astringent and has calming effects. It works in relieving coughs and calming asthma attacks, as well as in the disposal of worms (watermelon rind) and the treatment of skin flakes [14-16]. The skin, together with the seeds and rind, is used as animal feed or ends up as agricultural waste (biomass waste) $[17,18]$.

Additionally, due to the high content of unsaturated fatty acids, SB oil is a valuable source of nutrients (e.g., flavonoids and isoflavonoids, phenolic acids, phytosterols, proteins, and peptides), B vitamins, minerals (e.g., copper, manganese, molybdenum, phosphorus, potassium), and omega-3 fatty acids (alpha-linolenic acid)). [19].

Nutraceutical and pharmaceutical food products are gaining an increasing market share due to the aging global population, increasing the interest in preventive and curative foods, as well as food supplements (dietary supplement) containing oils. The utility of solubilizing lipid-based formulations for improving the gastrointestinal (GI) absorption of poorly water-soluble, hydrophobic bioactives is well documented in the literature [20].

Alginate encapsulation of lipids in the form of beads was suggested to be a potential method for manipulating the profile of lipid absorption in healthy subjects [21] or in reducing food intake and appetite sensations [22]. 
The encapsulation of oils using various techniques has become increasingly popular as a promising preservation method [23]. Therefore, studies have been carried out to optimize process factors for the encapsulation of oils with maximum efficiency [24,25].

Microencapsulation (ME) is one such technique, whereby small particles or liquid droplets (e.g., oil droplets) are coated or embedded in a homogenous or heterogonous matrix (hydrogel) to form small capsules or beads in both dry- and wet-form products. Microcapsule types can be classified into basic categories, such as simple microcapsules, irregular microcapsules, multiwall microcapsules, multicore microcapsules, matrices (hydrogel beads), and microcapsule assemblies [26,27].

Several encapsulation techniques for SB oil have been studied in order to protect it against environmental conditions and improve its oxidative stability, including spraydrying of SB oil emulsions made of whey protein and lactose, maltodextrin, chitosan, and CS-EGCG covalent conjugates (CSEG); electrostatic atomization of SB oil WO emulsions made of glycine and taurine; and ultrasound-assisted microcapsules made solely of unmodified or bare bovine liver, rabbit liver, and oyster glycogen or phytoglycogen.

The response surface methodology (RSM) is used to model the effects of different independent variables (parameters) on the extraction of phenolic compounds from different plants [28-31]. In the present study, RSM was applied in the optimization of ultrasoundassisted extraction (UAE) of skin sap (SS) rich in phenolic compounds from watermelon (W) (Citrullus colocynthis) regarding 3 factors (intensity, concentration, extraction time) and 3 levels and including 20 tests (runs). The obtained results were compared with the results obtained using percolation as a conventional extraction method [28].

The WSS extract obtained using the optimized UAE method applying RSM was added to SB oil and its antioxidant effect was compared to the antioxidant effect of the WSS extract obtained using the percolation method and by adding synthetic antioxidant BHT to SB oil. A control sample of SB oil (without antioxidants) was used as the reference.

\section{Materials and Methods}

The experimental design is represented in Figure 1.
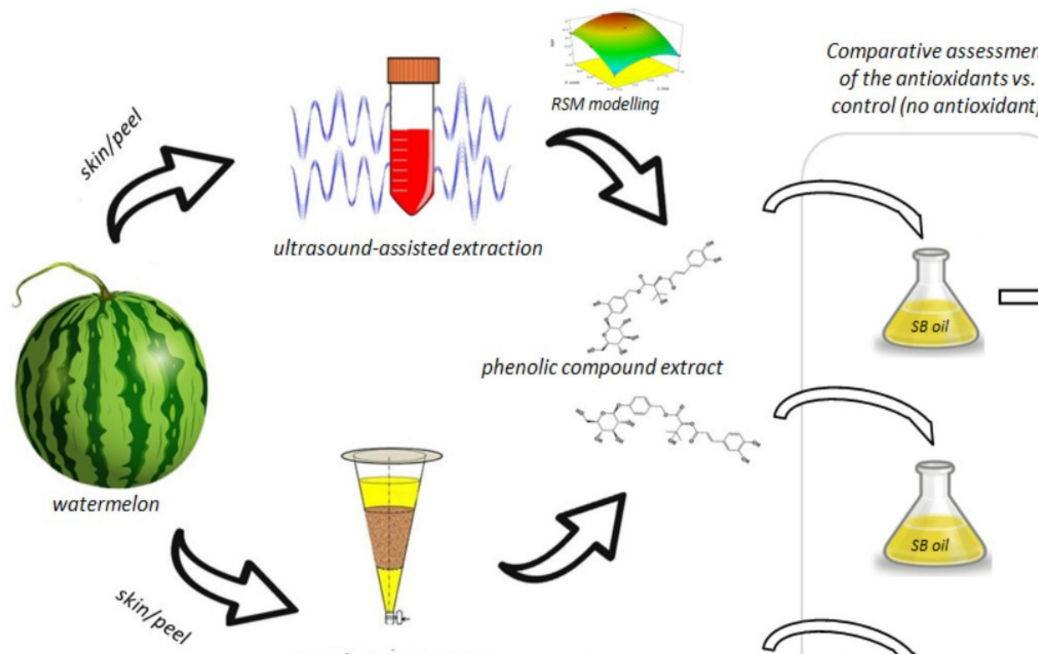

ultrasound-assisted extraction
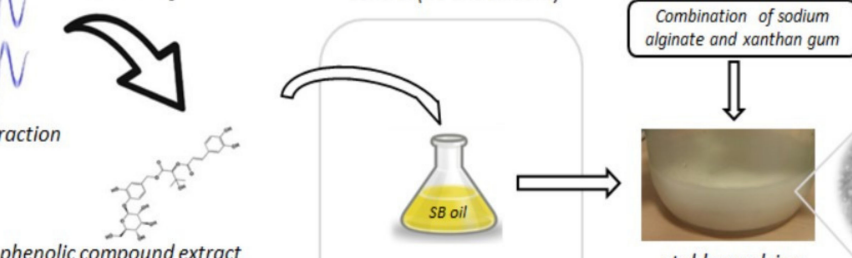

stable emulsion

phenolic compound extract
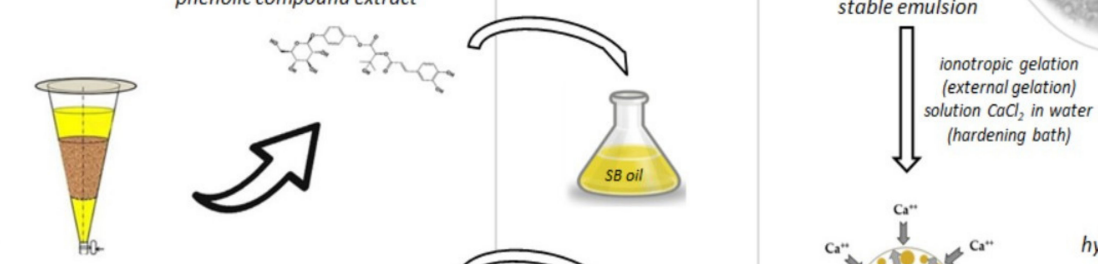

percolation extraction
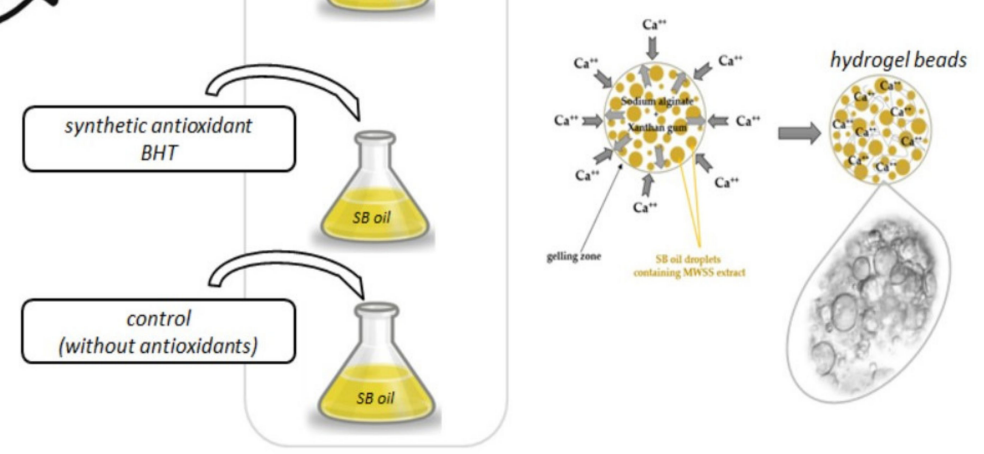

Figure 1. Experimental design. 


\subsection{Materials}

\subsubsection{Plant Material}

Fresh fully-grown fruits of C. lanatus (colocynth or Abu Jahl watermelon type) were purchased from a local market in Peshwar city, Pakistan (shortest time to mature, about 70 to 75 days).

To reduce the respiratory and biological activity, the fruits were stored until examination in a refrigerator at $4{ }^{\circ} \mathrm{C}$. The skin was peeled off from the whole fruit, washed, then used further in our study. The skins of the fruits were separated using a sharp knife and the thickness of the skins was measured using a caliper to equal $3 \mathrm{~mm}$. Then, a large volume of skins (around $20 \mathrm{~kg}$ ) was prepared and stored in the refrigerator for extraction and other experiments. The skins were sun-dried (exposed to direct sunlight for 5 days at temperatures of 35 to 40 degrees) in metal trays with high heat transfer and nets placed over them, then they were powdered and milled using an electric mill passing over a 40 mesh sieve (electric grinder, mkm6000, Bosch, Gerlingen, Germany), with particles ranging between $0.42-0.5 \mathrm{~mm}$. The skins were further stored for the next tests in a dark, cold, and dry area at $15^{\circ} \mathrm{C}$ and with humidity of less than $1 \%$.

\subsubsection{Materials}

Natrium alginate and xanthan gum were purchase from FMC Biopolymer Germany $\mathrm{GmbH}$ (Hamburg, Germany). All materials, solvents, and chemicals used in this study were of the highest purity grade and were purchased from Merck (Hamburg, Germany) and Sigma-Aldrich (Hamburg, Germany), including thiobarbituric acid ( $\geq 98 \%$ ), trichloroacetic acid $(\geq 99 \%)$, calcium chlorides $\left(\mathrm{CaCl}_{2}\right)(0.96 \%)$, heptane $(99.00 \%)$, ethanol $(70 \%)$, hydrochloric acid, gallic acid, and soybean oil.

\subsection{C. colocynthis Watermelon Skin Extration \\ 2.2.1. Percolation Extraction}

The percolation protocol used by $[32,33]$ was slightly adapted. The powdered sample was mixed with a solvent mixture at a ratio of 1:8 and stirred with a magnetic stirrer for $15 \mathrm{~min}$ at ambient temperature $\left(25^{\circ} \mathrm{C}\right)$. The solvent mixture was as follows: ethanol $70 \%$ and hydrochloric acid $1 \mathrm{~N}$, at a ratio of 15:85. This was then filtered under vacuum conditions using a Buchner funnel with Whatman No. 1 filter paper, then it was condensed using a rotary evaporator (Laborate Model 400, Arian Company, Sabzevar, Iran) at $35^{\circ} \mathrm{C}$. Finally, the obtained sap extract was dried under vacuum conditions at $40{ }^{\circ} \mathrm{C}$ (vacuum dryer, VACDR600-1500, Sabzevar, Iran) and stored in an enclosed container that was impervious to air at $4^{\circ} \mathrm{C}$.

\subsubsection{Ultrasound-Assisted Extraction (UAE)}

Saps were prepared according to the plant material extraction method, except the sample and solvent mixtures were exposed to ultrasound waves at ambient temperature for 10, 20, and $30 \mathrm{~min}$ and intensities of 20,60, and $100 \mathrm{kHz}$, respectively [34]. Ultrasound treatment was performed at 400 W (Vira Bakr Trade Model: vCLEAN1-L2, Sabzevar, Iran), with $\mathrm{H}$ probes made of titanium measuring $7 \mathrm{~mm}$ in diameter and $100 \mathrm{~mm} /$ cycle in length.

\subsection{Sample Preparation for Antioxidant Tests in Soybean Oil}

A standard amount of $0.04 \%$ of each WSS antioxidant extract (obtained by percolation and UAE extractions) and $0.1 \% \mathrm{w} / \mathrm{v}$ of BHT were separately added in $15 \mathrm{~g}$ of SB oil. As the control sample, soybean oil without any added antioxidants was used under the same conditions mentioned above. All samples were heated on a hot plate at $180^{\circ} \mathrm{C}$ for $2 \mathrm{~h}$ by maintaining a constant temperature throughout the study. Then, the samples were cooled down to room temperature $\left(25^{\circ} \mathrm{C}\right)$ and subjected to further characterization immediately. Experiments were carried out in triplicate. 


\subsection{Analytical Methods}

\subsubsection{Measuring the Amounts of Phenolic Compounds of WSS}

The total amounts of phenolic compounds were measured using the Folin-Ciocalteau method, an antioxidant assay based on electron transfer, which measures the reductive capacity of an antioxidant [35]. Gallic acid (Merck, Hamburg, Germany) was used to draw standard curves. The total amount of gallic acid in the sap was calculated by using the obtained equation from the standard curve and the results were expressed as milligrams of gallic acid per gram of extract [36].

\subsubsection{Measuring DPPH Radical Scavenging Activity Assay}

Evaluation of antioxidant activity was measured by examining the free radical scavenging activity of 2,2-diphenyl-1-picrylhydrazyl (DPPH). DPPH is a stable radical compound with a purple color that is revived by electron donor elements or hydrogen (antioxidant compounds), whereby it turns to a yellow color.

The ability of different compounds and saps to give hydrogen atoms or electrons can be measured based on the color or by reducing the amount of UV absorbance of the diphenyl-1-picrylhydrazyl solution in methanol. A stable radical composition of diphenyl1-picrylhydrazyl can be used as an indicator in this way. Thus, $50 \mathrm{~mL}$ samples of different concentrations of sap in methanol, each in $2 \mathrm{~mL}$ of $0.004 \%$ diphenyl-1-picrylhydrazyl, were added separately. After $90 \mathrm{~min}$ of incubation at room temperature, the absorbance levels of the samples at $517 \mathrm{~nm}$ were read in front of a witness (gallic acid solution was used for the calibration curve). The percentages of free radical scavenging diphenyl-1-picrylhydrazyl were calculated using Equation (1):

$$
\text { scavenging activity }(\%)=[(\mathrm{A}-\mathrm{B}) / \mathrm{A}] \times 100
$$

where: $\mathrm{A}=$ absorption of control samples; $\mathrm{B}=$ absorption of extract samples.

\subsubsection{Measuring the Acid Value of Oil}

Here, $25 \mathrm{~mL}$ of neutralized ethyl alcohol was added to the sample using sodium hydroxide $0.1 \mathrm{M}$. Then, the consumption rate of the sodium hydroxide $0.1 \mathrm{~N}$ in terms of oleic acid was determined based on titration (AOAC method) according to the following equation, with the help of three drops of phenolphthalein indicator (2):

$$
\text { Acid value }=\mathrm{N} \times \mathrm{V} \times 56.1 / \mathrm{W}
$$

$\mathrm{N}=$ normality

$\mathrm{V}=$ volume of sodium hydroxide titrant used $(\mathrm{mL})$

$\mathrm{W}=$ weight of the fatty oil being examined $(\mathrm{g})$

\subsubsection{Thiobarbituric-Acid-Reactive Substances (TBARS) Assay}

In a $250 \mathrm{~mL}$ Erlenmeyer flask, $1 \mathrm{~g}$ of sample and $1 \mathrm{~mL}$ of $0.75 \%$ solution of thiobarbituric acid and $2 \mathrm{~mL}$ of a solution of $35 \%$ trichloroacetic acid ( $\geq 99 \%)$ were added. The mixture was placed in a boiling water bath for $20 \mathrm{~min}$, after which time the solution was dissolved. The sample was centrifuged at $3000 \mathrm{rpm}$ for $3 \mathrm{~min}$. The aqueous phase was removed with a syringe and transferred to a spectrophotometric tube. The sample absorbance was recorded at $532 \mathrm{~nm}$ (UV-VIS-NIR Spectrophotometer UV-3600 Plus Series, Shimadzu, Kyoto, Japan). The absorbance of the sample at the mentioned wavelength was considered an indicator of thiobarbituric acid. The final concentration of thiobarbituric acid was $0.67 \%$.

\subsection{Response Surface Methodology}

The response surface methodology (RSM) is a statistical approach that involves a multivariate quadratic regression equation to study the combined effects between independent variables and the response and to obtain the optimal conditions [37]. This experimental 
methodology is an effective tool that clarifies the chemical or biochemical processes by using the shortest time with the least number of experiments. It is also a good way to analyze the influences among different variables. The effects of the intensity of sound (X1), concentration of sap (X2), and extraction time (X3) were chosen in the extraction process. According to the results from preliminary experiments, a three-level, four-factor Box-Behnken design (BBD) was employed in this investigation. The extended values for these parameters for the three levels are tabulated in Table 1. Design Expert software version 11 (StatEase, MN, USA) was used for the optimization method and the diagrams were drawn using the neural network method.

Table 1. Extended values of parameters.

\begin{tabular}{cccc}
\hline & Levels & & Factors \\
\cline { 1 - 2 } Upper & Center & Lower & $\left(\mathrm{X}_{1}\right)(\mathrm{kHz})$ (Intensity of sound) \\
100 & 60 & 20 & $\left(\mathrm{X}_{2}\right)(\mathrm{ppm})$ (Concentration of sap) \\
150 & 100 & 50 & $\left(\mathrm{X}_{3}\right)(\mathrm{min})$ (Extraction time) \\
15 & 10 & 5 & \\
\hline
\end{tabular}

With 8 replications in the central point, the total number of experiments was measured as 20 according to Formula (3):

$$
\mathrm{N}=2 \mathrm{k}(\mathrm{k}-1)+\mathrm{NC},
$$

where $\mathrm{k}$ is the number of factors and NC is the number of replications in the central point.

The matrix of the design experiments with the corresponding responses is shown in Table 2.

Table 2. Matrix of design experiments with responses.

\begin{tabular}{ccccc}
\hline $\begin{array}{c}\text { Intensity of Sound } \\
(\mathbf{k H z})\end{array}$ & $\begin{array}{c}\text { Concentration } \\
(\mathbf{p p m})\end{array}$ & $\begin{array}{c}\text { Time } \\
(\mathbf{m i n u t e s})\end{array}$ & $\begin{array}{c}\text { DPPH } \\
\mathbf{( \% )}\end{array}$ & $\begin{array}{c}\text { Folin-Ciocalteau (Milligrams of } \\
\text { Gallic Acid per Gram of Extract) }\end{array}$ \\
\hline 100 & 200 & 10 & $56.80 \pm 0.2$ & $18.25 \pm 0.2$ \\
60 & 200 & 5 & $49.60 \pm 0.3$ & $14.85 \pm 0.1$ \\
20 & 200 & 10 & $39.14 \pm 0.25$ & $15.85 \pm 0.25$ \\
60 & 200 & 15 & $44.79 \pm 0.4$ & $14.37 \pm 0.5$ \\
60 & 120 & 10 & $49.54 \pm 0.5$ & $14.88 \pm 0.2$ \\
20 & 120 & 15 & $25.39 \pm 0.2$ & $15.00 \pm 0.3$ \\
100 & 120 & 15 & $49.2 \pm 0.25$ & $14.37 \pm 0.4$ \\
100 & 120 & 10 & $43.17 \pm 0.4$ & $16.07 \pm 0.1$ \\
100 & 40 & 5 & $50.52 \pm 0.2$ & $12.80 \pm 0.5$ \\
60 & 40 & 10 & $39.65 \pm 0.1$ & $12.57 \pm 0.3$ \\
60 & 40 & 15 & $30.79 \pm 0.3$ & $11.39 \pm 0.1$ \\
\hline
\end{tabular}

\subsection{Preparation and Evaluation of Emulsion}

\subsubsection{Emulsion Preparation}

A mixture of sodium-alginate and xanthan gum $(\mathrm{AXG})(1.5: 0.5 \mathrm{w} / \mathrm{w})$ was dissolved in deionized water under magnetic stirring for $\sim 30 \mathrm{~min}$ at $1000 \mathrm{rpm}$ and at room temperature. The polymers solution was blended with SB oil (5:1 ratio) containing WSS antioxidant was extracted via UAE using a high-shear homogenizer (Ultra-Turrax, Cluj-Napoca, Romania; $5000 \mathrm{rpm}$ ) to form an oil-in-water (OW) emulsion.

\subsubsection{OW Emulsion Stability Evaluation}

The OW emulsion stability was evaluated according to Gangurde et al. [38] and as previously described by Rusu et al. [39]. 
The OW emulsion stability was measured based on the \% of separation (4):

$$
\% \text { separation }=\mathrm{H}_{1} / \mathrm{H}_{0} \times 100
$$

where $\mathrm{H}_{0}$ represents the $\mathrm{OW}$ emulsion's initial height and $\mathrm{H}_{1}$ represents the stable $\mathrm{OW}$ emulsion after $24 \mathrm{~h}$ (upper phase height) at room temperature

\subsection{Preparation of Hydrogel Beads}

The stable OW emulsion obtained was then dropped (dropping method) into a stirred $2 \%(\mathrm{w} / \mathrm{v})$ solution of $\mathrm{CaCl}_{2}$ at a concentration of $1 \mathrm{mM}$ in water (as a hardening water bath), using a peristaltic pump with an injector measuring $0.4 \mathrm{~mm} \times 20 \mathrm{~mm}$, and was then stirred for $\sim 1 \mathrm{~h}[25,39]$. After $1 \mathrm{~h}$ of curing, the hydrogel beads obtained using ionotropic gelation and the cross linking technique were separated from the hardening bath, washed with deionized water, then they were put on Petri dishes covered with filter paper to remove the remaining water.

\subsection{Determination of Encapsulation Efficiency}

The normalized absorption spectrum of SB oil with WSS antioxidant extracted via UAE was performed in heptane and measured in the wavelength range of 300-550 nm, which was related to the presence of unsaturated fatty acids, using a Lambda 2 ultraviolet (UV) spectrophotometer. The maximum absorbance was detected and recorded.

The encapsulation efficiency (EE) was calculated by taking into consideration the maximum absorption peaks before and after encapsulation. The maximum absorption of SB oil with antioxidant was assayed spectrophotometrically using heptane as a solvent. The hydrogel beads were crushed using a mortar after the encapsulation but the prior to spectrophotometric assay.

The previously described Formula (5) was used with the following modifications [8]:

$$
(\mathrm{EE} \%)=\mathrm{C} 1 /(\mathrm{DF} \times \mathrm{C} 2) \times 100
$$

where $\mathrm{C} 1$ is the maximum absorption peak in hydrogel beads containing SB oil with antioxidant, $\mathrm{C} 2$ is the maximum absorption peak of SB oil with antioxidant before encapsulation, and DF is the dilution factor of SB oil with antioxidant according to the added encapsulation material (in our case DF $=1$ )

\subsection{Analysis of Hydrogel Beads}

\subsubsection{Size Analysis}

The obtained hydrogel bead areas, perimeters, and diameters were measured using the UTHSCSA ImageTool 3.0 software (University of Texas Health Science Center in San Antonio, TX, USA) [40,41].

\subsubsection{Morphological Characterization}

The obtained hydrogel beads sizes and aspects were characterized under light microscopy with a Zeiss Axioskop 2 microscope (Cluj-Napoca, Romania).

\subsection{Statistical Analysis}

Analysis of Variance (ANOVA)

An ANOVA table was used in order to determine the significant parameters and the proposed model for measuring antioxidant activity, with the table given below. P values below 0.05 for each parameter indicate significance at the confidence level of 0.95 . P values are also related to a lack of fit greater than 0.05 , indicating a lack of significance of the related error to the model error, with the remainder related to the net error (random).

The results are expressed as the mean value with the standard deviation (mean \pm S.D.) for each sample, with samples measured in triplicate $(n=3)$. Statistical analysis was 
performed using Student's $t$-test and differences were considered significant if the $p$-values were under 0.05 .

\section{Results and Discussions}

\subsection{Optimization Process Variables}

The optimal process variables for a response may provide an unfavorable answer according to analyzed the charts, meaning models should be introduced that satisfactorily optimize all the answers as much as possible. For this purpose, different time and logics contour plots that estimated the details of all answers were introduced in the optimal area. Under these circumstances, the inhibition power levels of free radicals were determined as $57.084 \%$ and $18.248 \mathrm{~g}$ of the amount of phenol compounds. The aim of the extraction optimization in this study was to maximize the UAE extraction amount of antioxidants from WSS using RSM. In Table 3, the obtained values for the optimized extraction method vs. the conventional percolation method were determined. The extraction method used for the different natural compounds had an influence on their extraction rates and efficiency levels. Table 3 shows a comparison of the extraction rates of the phenolic compounds from WSS using UAE and percolation methods under the best extraction process conditions.

Table 3. Ultrasound-assisted extraction (UAE) (optimized extraction method) compared with the percolation method (conventional solvent extraction).

\begin{tabular}{ccc}
\hline Extraction Method & $\begin{array}{c}\text { Power Inhibitory Free } \\
\text { Radical (\%) }\end{array}$ & $\begin{array}{c}\text { Phenolic Compounds } \\
\text { (Grams) }\end{array}$ \\
\hline Optimized extraction & $57.084^{\mathrm{a}}$ & $18.248^{\mathrm{a}}$ \\
Percolation & $41.19^{\mathrm{b}}$ & $15.32^{\mathrm{b}}$ \\
\hline
\end{tabular}

a,b_in each column, averages with common letters were not statistically significantly different.

Finally, the obtained WSS optimal sample results were selected and compared with MWSS samples extracted via percolation method with an optimal concentration of $200 \mathrm{ppm}$. The results of the comparison showed the impact of the extraction type on the parameters, showing significant differences between the two extraction methods $(p<0.05)$. Finally, these two samples and the synthetic antioxidant BHT were added to soybean oil and were studied against the control sample.

\subsection{Interpretation of Free Radical Scavenging Activity of Diphenyl-1-Picrylhydrazyl (DPPH)}

Figure 2 shows the time and intensity of the sound effects in the extraction method. The amount of antioxidant activity increased significantly by increasing the time and intensity. The antioxidant activity increased as time and sound intensity increased from $5 \mathrm{~min}$ to $10 \mathrm{~min}$ with the highest DPPH radical scavenging potential of $54 \pm 0.44 \%$, although decreased from minute 10 to minute 15 under $32 \pm 0.2 \%$ activity, as shown in Figure 2 .

The intensification of the mass transfer due to the collapse of cavitation bubbles near the cell walls is the reason the extracted amount of phenol compounds increased in this section, resulting in better contact between the solvent and plant material. In addition, the rapid flow of ultrasonic waves produced at the time of the collapse of cavitation bubbles had an effect, which acted as a micro pump, meaning the solvent was forcibly driven into the cell to produce the intended combinations [42].

Cycles of expansion and contraction caused by the environment and the propagation of sound waves in the solid-liquid phase lead to the formation of bubbles, which continue to grow and then finally disintegrate. This act causes the solid and liquid particles to change and speed up under ultrasonic action. As a result, the solvent material spreads rapidly from a solid to a solvent. In addition, other effects such as the spread of emulsifier fixation and damage to tissues also help to increase the extraction of raw material components. It is possible to reduce the extraction across longer time periods because of the oxidation (due to ultrasound exposure) [43]. 


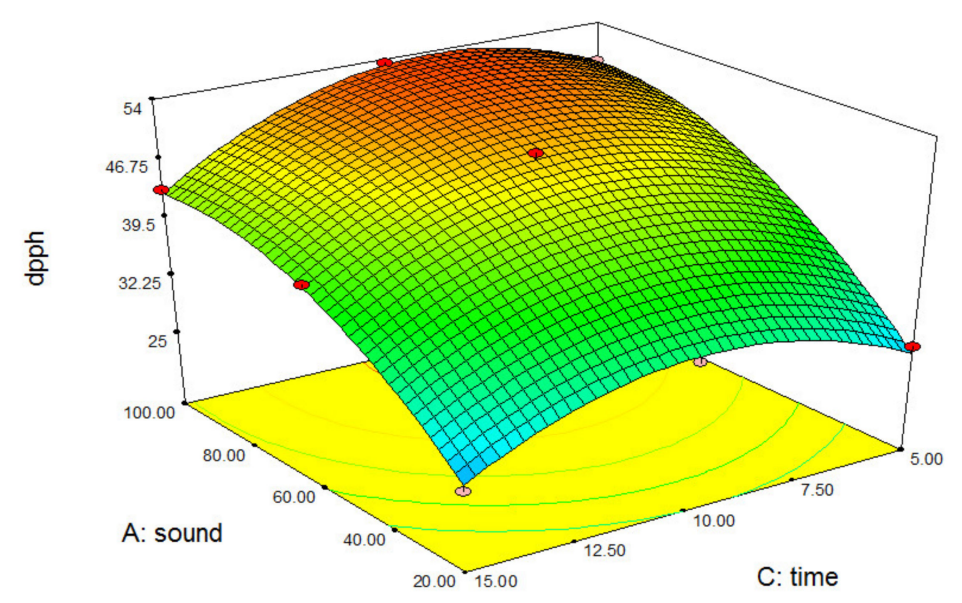

Figure 2. Response surface plot representing the effects of sound and time on diphenyl-1picrylhydrazyl (DPPH).

Ma and colleagues [44] tested the extraction of hesperidin from mandarin (Citrus reticulata) skins with the help of ultrasound waves. The outputs of the antioxidant compounds for the 3 frequencies of 20,60, and $100 \mathrm{kHz}$ were time-dependent and significantly increased. These outputs increased from 20 to $60 \mathrm{~min}$ at a high rate but increased slowly from 60 to $100 \mathrm{~min}$. The most effective extraction period to achieve the best antioxidant compound concentrations across the 3 frequencies was considered to be around $60 \mathrm{~min}$. Zou et al. [45] assessed the extraction of mulberry antioxidants with ultrasonic assistance from 20 to $100 \mathrm{~min}$. It was found that the amount of antioxidant extract increased from 20 to $40 \mathrm{~min}$ and then was approximately constant from 40 to $100 \mathrm{~min}$, due to the balance between the solvent and extracted plant materials.

Figure 3 shows a three-dimensional display of time and sap concentration effects on DPPH. By increasing the time and sap concentration, the antioxidant activity increased significantly. The antioxidant activity increased with increasing time and sap concentration from 5 to $10 \mathrm{~min}$ but decreased from 10 to $15 \mathrm{~min}$. The results showed the effects of different concentrations of the WSS on the inhibitory activity of free radicals, while the scavenging activity of the extract significantly increased by increasing the sap concentration. As mentioned above, the WSS extract concentration of $200 \mathrm{ppm}$ (parts per million) had the highest amount of phenol compounds, meaning it had higher antioxidant properties and scavenging activity than the other treatments. It has been reported that DPPH has dose-dependent effects on plant saps. The free radical scavenging activity increased dramatically by increasing the sap concentration. The high contents of phenol compounds and flavonoids in this sap were consistent with the high levels of free radical and peroxidation inhibition. The time factor increases the mass transfer duration; therefore, the increasing trend of sap extraction with time seems logical. Khan et al. [46] studied the extraction of antioxidants from orange sap (Citrus sinensis L.) via UAE. The amount of antioxidant activity from the extracted sap was $54 \%$ compared to $42 \%$ when using a conventional extraction method (solvent extraction). The increased antioxidant capacity was attributed to the higher concentrations of phenol compounds. 


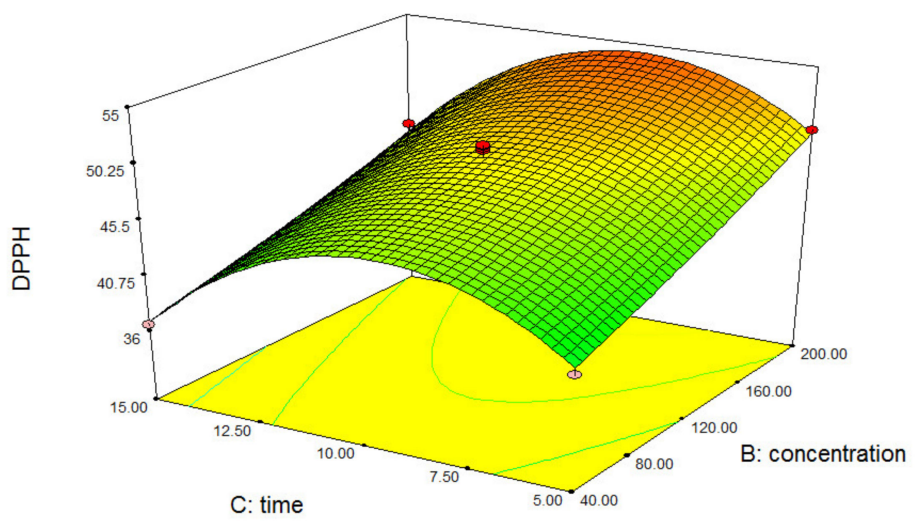

Figure 3. Three-dimensional figure showing the interactive effects of 3 factors (intensity, concentration, and time). The response surface plot represents the effects of the concentration and time on diphenyl-1-picrylhydrazyl.

\subsection{Interpretation of the Total Phenolic Content}

Figure 4a shows a three-dimensional display of the effects of the time and concentration. By increasing the time and sap concentration, the amount of phenol compounds increased significantly. The phenol compound concentration increased from 5 to $10 \mathrm{~min}$ with the increases in time and concentration, but decreased after 5 min (minute 15).

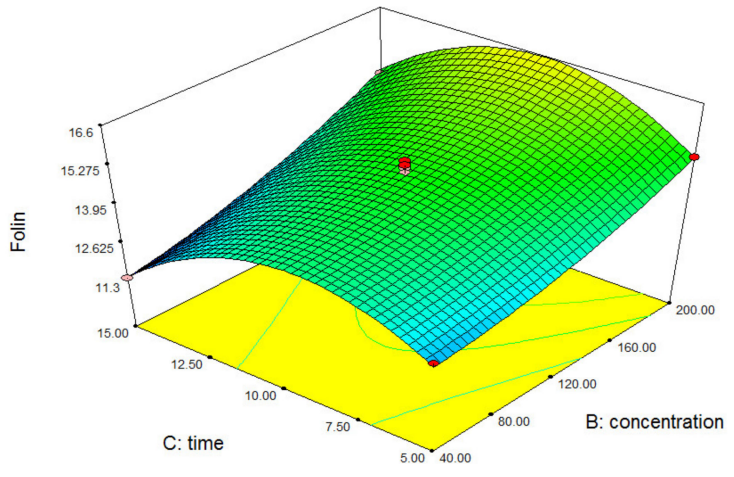

(a)

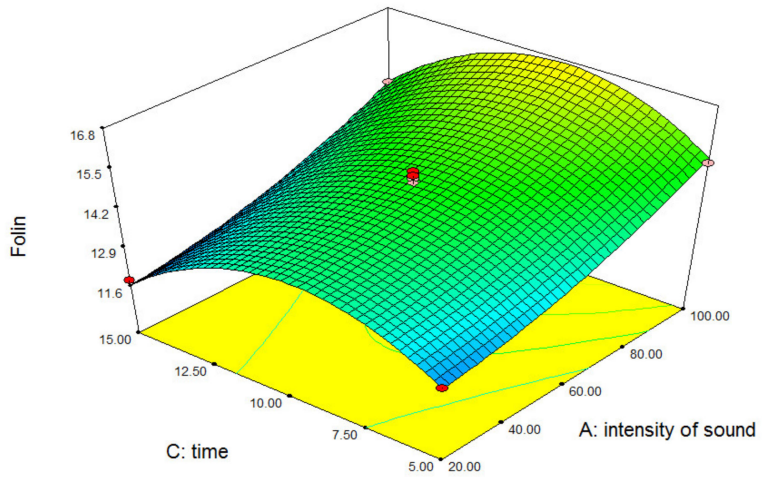

(b)

Figure 4. Three-dimensional figures of the interactive effects of 3 factors (intensity, concentration, time). Response surface plot representing the effect of: (a) concentration and time factors on Folin-Ciocalteau extraction; (b) sound and time factors on Folin-Ciocalteau extraction.

Figure $4 \mathrm{~b}$ shows the effect of the extraction time and frequency on the performance of the watermelon skin sap, as can be seen from Table 4 . The frequency had a significant effect over time on the extraction of phenol compounds. The results showed that the sap output increased with increasing frequency.

The reason for the higher extraction amount of phenol compounds using UAE can be attributed to the capitation phenomenon. In fact, cycles of expansion and contraction in the environment caused by the emission effect of sound waves in the solid-liquid phase lead to the formation bubbles, which continue to grow and then finally disintegrate. Wang et al. [47] also showed that the amount of phenol compounds extracted from wheat bran can be increased using the optimized UAE method. The phenol compound concentration increased significantly from 10 to $30 \mathrm{~min}$ but decreased significantly after $30 \mathrm{~min}$ and until $50 \mathrm{~min}$. 
Table 4. ANOVA results for Folin-Ciocalteau extraction.

\begin{tabular}{ccccccc}
\hline Source & S. Squares & df & M. Square & F. Value & $p$-Value & Significance \\
\hline Model & 47.42 & 9 & 5.27 & 194.54 & $<0.0001$ \\
A-intensity of sound & 15.12 & 1 & 15.12 & 558.41 & $<0.0001$ \\
B-concentration & 13.76 & 1 & 13.76 & 508.03 & $<0.0001$ \\
C-time & 1.27 & 1 & 1.27 & 47.02 & $<0.0001$ \\
AB & 0.3 & 1 & 0.3 & 11.17 & 0.0075 \\
AC & $4 \times 10^{-4}$ & 1 & $4 \times 10^{-4}$ & 0.015 & 0.9057 \\
BC & 0.22 & 1 & 0.22 & 8.02 & 0.0178 \\
A`2 $_{B^{\wedge} 2}$ & 0.85 & 1 & 0.85 & 31.24 & 0.0002 \\
C`2 $_{\text {Residual }}$ & 0.63 & 1 & 0.63 & 23.39 & 0.0007 \\
Lack of Fit & 16.55 & 1 & 16.55 & 611.05 & $<0.0001$ \\
Pure Error & 0.27 & 10 & 0.027 & & 0.1215 \\
Cor Total & 0.15 & 3 & 0.049 & 2.76 & \\
\end{tabular}

As can be seen in Figure $4 b$, the results show increases in the amount of phenolic compounds in the sap with increases in the sap concentration from 50 to 200 ppm, leading the antioxidant properties being enhanced. The antioxidant properties of fruits and vegetables are due to the high concentrations of phenolic compounds. There is a positive correlation between the amount of phenolic compounds and the antioxidant power of a plant.

An ANOVA table is given below for all variables (Table 5 shows DPPH extraction and Table 4 shows Folin-Ciocalteau extraction). There were at least four affective variables for each direct variable, as can be seen.

Table 5. ANOVA results for DPPH extraction.

\begin{tabular}{ccccccc}
\hline Source & S. Squares & df & M. Square & F. Value & $p$-Value & Significance \\
\hline Model & 1353.53 & 9 & 150.39 & 157.82 & $<0.0001$ \\
A-intensity of sound & 713.1 & 1 & 713.1 & 748.32 & $<0.0001$ \\
B-concentration & 135.05 & 1 & 135.05 & 141.73 & $<0.0001$ \\
C-time & 38.02 & 1 & 38.02 & 39.9 & $<0.0001$ \\
AB & 1.07 & 1 & 1.07 & 1.12 & 0.314 \\
AC & 1.66 & 1 & 1.66 & 1.75 & 0.2158 \\
BC & 0.69 & 1 & 0.69 & 0.72 & 0.4151 \\
A $^{\wedge}$ & 143.74 & 1 & 143.74 & 150.84 & $<0.0001$ \\
B $2^{\wedge} 2$ & 0.65 & 1 & 0.65 & 0.68 & $<0.0001$ \\
Residual & 242.61 & 1 & 242.61 & 254.6 & 0.6267 \\
Lack of Fit & 9.53 & 10 & 0.95 & & N-Sig \\
Pure Error & 1.99 & 3 & 0.66 & 0.62 & \\
Cor Total & 7.54 & 7 & 1.08 & &
\end{tabular}

The coefficient of determination $\left(R^{2}, R^{2}\right.$ Adj, $R^{2}$ Pred $)$ values for the two responses are given in Tables 6 and 7. Large determination coefficients values were adjusted, while the proximity to the coefficient of determination determined the validity of the proposed model. If the $\mathrm{R}^{2}$ is closer to 1 , the models are more powerful and the response can be predicted better. Values related to the predicted determination coefficient were greater than 0.94, indicating the validity of the model for data that were not mentioned in the model.

Table 6. Determination parameters used to assess and validate the model for DPPH extraction.

\begin{tabular}{cl}
\hline R-Squared & 0.9943 \\
\hline Adj R-Squared & 0.9892 \\
Pred R-Squared & 0.9474 \\
\hline
\end{tabular}


Table 7. Determination parameters used to assess and validate the model for Folin-Ciocalteau extraction.

\begin{tabular}{cc}
\hline R-Squared & 0.9837 \\
\hline Adj R-Squared & 0.9711 \\
Pred R-Squared & 0.9303 \\
\hline
\end{tabular}

According to variance analysis tables and parameters used determine the validity of the model and taking into account the main factors, quadratic polynomial models used to measure the antioxidant activity via Table 5 were used to form Equation (6):

$\mathrm{DPPH}=+49.54+9.44 \mathrm{~A}+4.11 \mathrm{~B}-2.18 \mathrm{C}-0.52 \mathrm{AB}-0.65 \mathrm{AC}-0.42 \mathrm{BC}-5.61 \mathrm{~A} 2+0.38 \mathrm{~B} 2-7.29 \mathrm{C} 2$,

\subsection{Effect of Antioxidants on Oxidation of Soybean Oil}

\subsubsection{Determination of Acidity Index}

According to Figure 5, due to the effect of the sap type, the most acidity was observed in the control sample with a rate of 0.53 , while the lowest acidity was observed in the optimum sample (optimized extraction UAE) with a rate of 0.42 , with significant differences $(p<0.05)$. Reviewing the effects of the sap type on the acidity index, it was observed that the acidity index decreased significantly when the antioxidant compound concentration increased by $20 \%$. This was due to the presence of certain phenol compounds in the skin of watermelon (C. colocynthis), which neutralize free radicals of fatty acids and proxy radicals, meaning the oxidation of glucose increases, ultimately leading to oxidation reductions.

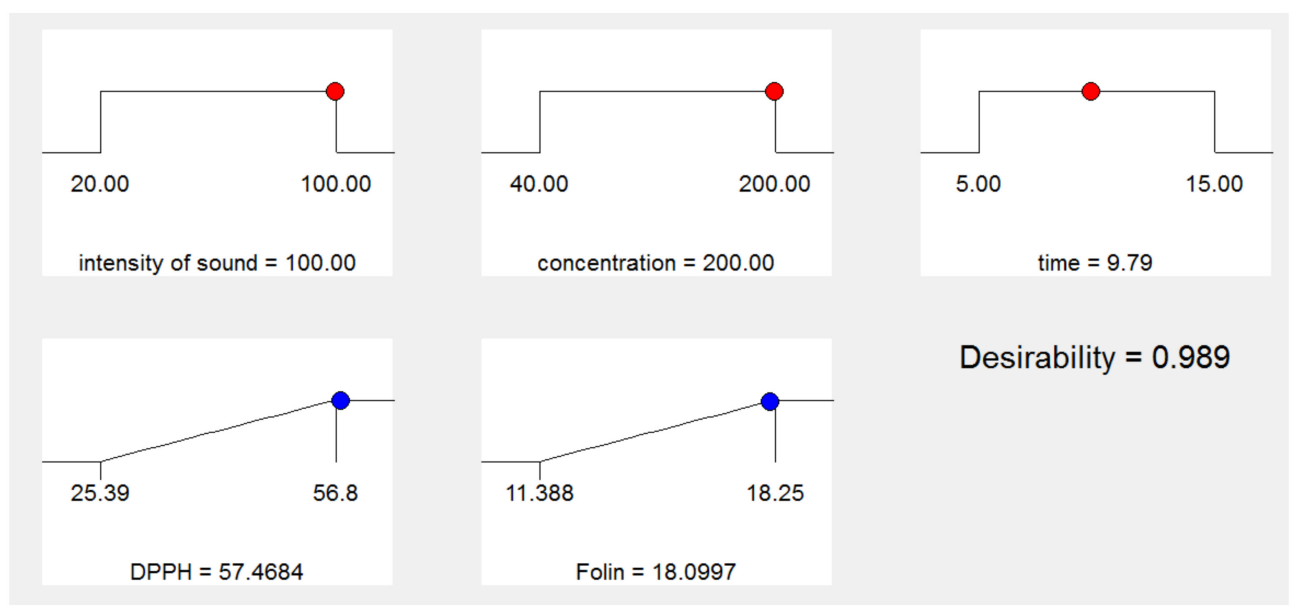

Figure 5. The optimization factors for diphenyl-1-picrylhydrazyl and Folin-Ciocalteau extraction.

\subsubsection{Determination of Thiobarbituric Acid}

The results showed that WSS had higher antioxidant activity and the lowest amount thiobarbituric acid. According to a comparison of the results, the highest mean value for thiobarbituric acid was from the control sample (no antioxidant) with a value of 0.49 , while the lowest value was for WSS at 0.34 .

The extraction of natural antioxidants could be beneficial, as they could be competitors or even replacements for synthetic antioxidant BHT. The thiobarbituric acid index values decreased with the increasing antioxidant activity of the WSS.

Watermelon skin, an important by-product, is a rich source of phenolic compounds (with catalytic antioxidant effects). The RSM was applied in this study to determine the optimal extraction conditions in terms of the time (minutes), concentration (ppm), and sound intensity $(\mathrm{kHz})$. The procedure was evaluated in terms of the sap extraction yield and antioxidant activity. The results of the present study can be applied to obtain the optimum conditions for WSS. The results suggest that watermelon skin has great potential 
as a raw material for the extraction of natural antioxidants and can be successfully used for food processing.

Recently, several researchers investigated the best extraction conditions for the UAE of different phenolic compounds from plants, fruits, and vegetables through the RSM. This seems to be a good method for optimizing experimental processes by examining the influence of process variables and their interactions on the investigational outcomes, while at the same time reducing the number of tests [48-53]. Most studies have proven that RSM is an effective method for optimizing the extraction of flavonoids from various plants.

Additionally, the UAE of some bioactives from different watermelon parts (e.g., seeds, peel) was investigated using the RSM [44-56]. To our knowledge, this is the first study investigating the antioxidant effects on edible oils; in our study we used SB oil, the most commonly produced oil crop in the world, which is associated with numerous health benefits [57].

Further, the SB oil containing the antioxidants extracted under optimized conditions was subjected to coating using a blend of natural polysaccharides, namely alginate and xanthan gum, in hydrogel beads via ionotropical gelation.

\subsection{Evaluation of Oil-in-Water Emulsions}

The OW emulsion (Figure 1) had a milky, slightly yellow appearance. No creaming or phase separation was observed under centrifugation.

The light microscopy imaging of the OW emulsion revealed the presence of oil droplets, whose size varied between 5 and $40 \mu \mathrm{m}$ (majority $\geq 10 \mu \mathrm{m}$ ), which were highly dispersed (Figure 6a). We assume that the stability of the obtained OW emulsion could be to the emulsifying function of SB oil, as it is a major source of lecithin, which is most commonly used as an emulsifier.

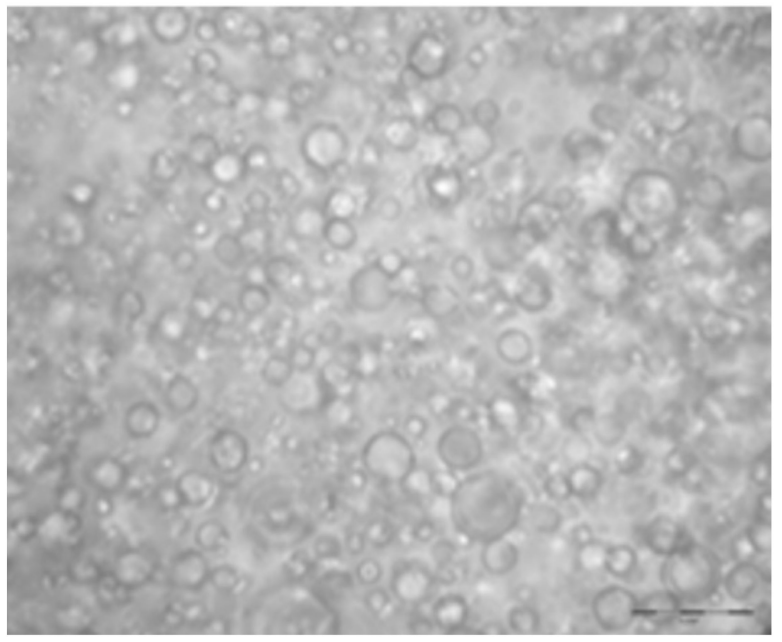

(a)

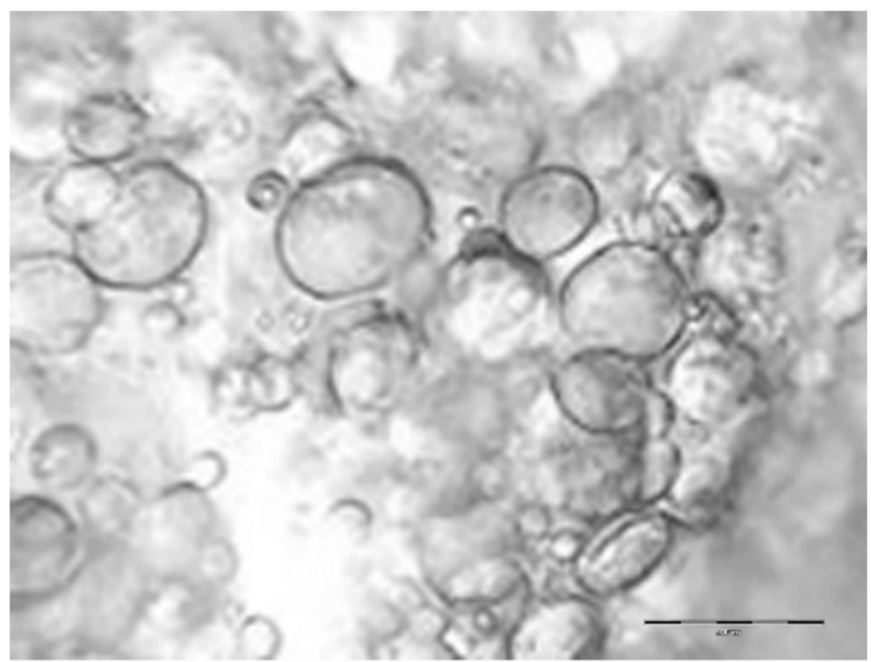

(b)

Figure 6. (a) Microscopic image of OW emulsion droplets (under $20 \times$ light microscopy magnitude, scale represents $100 \mu \mathrm{M}$ ). (b) SB oil droplets in calcium-crosslinked AGX hydrogel bead (under $20 \times$ light microscopy magnitude, scale represents $100 \mu \mathrm{M})$.

\section{Encapsulation Efficiency}

The EE $\%$ was calculated as $86 \%$, which was good according to other references [26,58].

\subsection{Hydrogel Bead Characterization}

The results of the measurements are presented in Table 8. The size of the hydrogel beads was determined from the apparent diameter, which came from the calculated diameter of an ideal circle with exactly the same area as the measured bead [59]. 
Table 8. Characteristics of hydrogel beads.

\begin{tabular}{cccc}
\hline Beads & Mean Area $\left(\mathbf{m m}^{\mathbf{2}}\right)$ & Mean Roundness & Mean Diameter (mm) \\
\hline Hydrogel beads obtained & $3.48 \pm 0.01$ & $0.84 \pm 0.04$ & $2.1 \pm 0.03$ \\
\hline
\end{tabular}

The roundness values varied from 0 to 1 . Almost spherical hydrogel beads were obtained, with diameters between 1.5 and $3.2 \pm 0.01 \mathrm{~mm}$.

\section{Discussions}

The results of this study have proven the positive effects of natural and synthetic antioxidants on the oxidative stability of vegetable oils for both edible and industrial uses, as already proven by numerous experimental studies. Ruger et al. [60] investigated the ability of various antioxidants and chelators (including TBHQ, BHT, hydroquinone, and ascorbyl palmitate) to delay viscosity in soybean oil, with autoxidation with TBHQ being the most effective approach.

Natural antioxidants from red pepper (Capsicum frutescens) oil added to soybean and sunflower oils showed their effectiveness by providing variable protection against lightinduced autoxidation [61]. Olive leaf extract encapsulated (microwave-assisted) by Arabic gum and maltodextrin was used in order to stabilize soybean oil, showing more oxidative protection activity compared to BHT [62].

A methanol extract of sesame cake in soybean, sunflower, and safflower oils was tested for its antioxidant activity, showing that the sesame cake extract had better antioxidant effects than BHT at 200 ppm; unfortunately it is still not economical to use sesame for antioxidant extraction [63].

Genetically engineered soybean seed (containing $83 \%$ oleic acid) provides oils that have about 30 times more oxidative and viscosity stability than conventional oil. However, as genetically modified organisms are a sensitive subject, the use of antioxidants is well recognized and accepted as a relatively cheap and effective method for obtaining oxidative stability improvements in oils. An ideal antioxidant is effective in low concentrations with minimal toxicity. The applicability of natural extracts that have been found to possess antioxidant activity, which have yielded encouraging results, is a topic of ongoing research. The next generation of safer, environmentally friendly, effective antioxidants is undoubtedly soon to come [64].

However, the extraction process used for phenolic compounds is a major factor in the antioxidant properties of the sap, along with the power, solvent, and time, which all significantly the composition of phenolic compounds in the sap [65]. The variability depends on the differences in the inner affinities of these compounds, especially the polarity of the forming molecules of the solvent [66]. Therefore, the type of solvent and extraction time are very important factors in the extraction process.

In addition, the extraction of molecules from biological materials using conventional methods, for example percolation, requires a lot of time and a large amount of solvent [19]. Applying new extraction methods over shorter extraction times is preferred (less timeconsuming), using low or moderate volumes of organic solvents, as such approaches are especially environmentally friendly. Extraction methods such as accelerated solvent extraction (ASE), microwave-assisted extraction (MAE), ultrasound-assisted extraction (UAE), and supercritical fluid extraction (SFE) are fast and effective methods for extracting effective components of plant origin [67]. UAE uses acoustic waves and is considered a simple alternative to many other extraction methods due to its low costs and impressive effects in maintaining and processing foodstuffs. As such, its application prospects are growing. The mechanical effects of ultrasound waves and the cavitation phenomenon created by the waves increase the permeability of solvents into plant cells, thereby increasing the mass transfer and the extraction efficiency at lower temperatures $[68,69]$. The samples in the ultrasonic probe are continuously placed in contact with the probe and have high capability and repeatability. In addition, the risks of sample contamination and foam 
generation are high, although the ultrasonic bath can operate on a wide range of samples simultaneously [70].

The encapsulation efficiency, storage stability, and minimization of oil release throughout digestion are very important for oils [71-77]. The encapsulation efficiency of SB oil using different matrices and capsule types was moderate. When using whey protein, the EE was moderate and of low quality when compared to sodium caseinate under certain storage conditions. On the other hand, the improved oxidative stability of SB oil was observed when encapsulated into a WO emulsion made of glycine and taurine [72].

The in vitro gastrointestinal digestion results revealed that coating SB oil bodies with maltodextrin and CS-EGCG covalent conjugates prior to spray-drying greatly decreased the release of oil from $85.2 \%$ to $45.3 \%$, demonstrating that this formulation has the potential to overcome stability drawbacks and minimize the degree of SB oil release throughout digestion [77].

Laccase-cross-linked, beet-pectin-coated SB oil bodies showed better stability under different conditions. It was shown that SB oil body emulsions stabilized with t-carrageenan were more stable in terms of creaming due to decreased flocculation than the emulsions stabilized with $\mathrm{k}$ or $\lambda$-carrageenan after $7 \mathrm{~d}$ storage. Additionally, SB oil body emulsions coated with a l-carrageenan layer at $\mathrm{pH} 3.0$ and 7.0 showed improved stability under environmental stress [78-81]. Apparently, SB oil bodies can be used as carriers to deliver phenolic compounds such as curcumin in order to improve the stability of the oil bodies and their release rate during digestion [82-84].

\section{Conclusions}

In this study, saps extracted from the skins of mountain watermelon were used successfully as an alternative source of natural antioxidants, as compared to BHT, a synthetic antioxidant. In general, the results of the analysis involving the response surface methodology, which was used to extract phenolic compounds, and the scale of the scavenging activity of free radicals further indicated that the optimal conditions were an extraction time of $31.9 \mathrm{~min}$ at $200 \mathrm{ppm}$ concentration and with an intensity of $100 \mathrm{kHz}$. According to the results, the extracted phenolic compounds amounted to $18.24 \mathrm{mg}$ and the scavenging activity of the free radicals from plant sap at the optimal point was reported as $57.842 \%$. The oxidative stability of the soybean oil in the control, percolation extraction, and optimization samples, as well as in the synthetic antioxidant, showed that ultrasound-assisted extraction using the response surface methodology has greater antioxidant effects in reducing the peroxide index, thiobarbituric acid index, and acidity index compared to control samples (without antioxidant) and synthetic antioxidant BHT. In this study, it has been proven again that natural additives have greater antioxidant activity than synthetic ones.

The three UAE process variables (time, concentration, and intensity) had significant impacts on the total phenolic extraction rates and their antioxidant effects on the oxidation stability of soybean oil.

In conclusion, the present study has demonstrated that a natural plant extract from mountain watermelon skin that was obtained via ultrasound-assisted extraction effectively protected soybean oil from lipid oxidation. Hydrogel beads were successfully prepared for use with soybean oil containing mountain watermelon skin sap extracted using sodium alginate as the major polymer and combined with hydrophilic xanthan gum to improve the entrapment of the oil via ionotropic gelation and the cross-linking technique. In this regard, the use of this technique will ensure the prolonged stability of encapsulated soybean oil for further applications.

Author Contributions: Conceptualization, M.F., E.A., M.T., Y.W.; investigation, M.F., E.A., R.A.J., Z.B., M.S., N.I., B.E.S.; data curation, M.F., E.A., R.A.J., Z.B., M.S., N.I., S.P.B.; writing—original draft preparation, M.F., E.A.; writing — review and editing, M.F., E.A., M.T., A.R., Y.W.; supervision, M.T., A.R., Y.W.; project administration, A.R., Y.W.; funding acquisition, A.R. All authors have read and agreed to the published version of the manuscript. 
Funding: The APC was funded, and this work was supported by a grant from the Romanian National Authority for Scientific Research and Innovation, CNCS-UEFISCDI, project number PN-III-P2-2.1PED-2019-1723, within PNCDI III.

Institutional Review Board Statement: Not applicable.

Informed Consent Statement: Not applicable.

Data Availability Statement: Data sharing is not applicable to this article.

Conflicts of Interest: The authors declare no conflict of interest.

\section{References}

1. United States Department of Agriculture Foreign Agricultural Service. Oilseeds: World Markets and Trade. 2021. Available online: https:/ / apps.fas.usda.gov/psdonline/circulars/oilseeds.pdf (accessed on 28 September 2021).

2. Galano, J.-M.; Lee, Y.Y.; Durand, T.; Lee, J.C.-Y. Special Issue on "Analytical Methods for Oxidized Biomolecules and Antioxidants" The use of isoprostanoids as biomarkers of oxidative damage, and their role in human dietary intervention studies. Free Radic. Res. 2015, 49, 583-598. [CrossRef] [PubMed]

3. Farooq, M.; Azadfar, E.; Rusu, A.; Trif, M.; Poushi, M.K.; Wang, Y. Improving the Shelf Life of Peeled Fresh Almond Kernels by Edible Coating with Mastic Gum. Coatings 2021, 11, 618. [CrossRef]

4. Ravi Kiran, C.; Sasidharan, I.; Soban Kumar, D.R.; Sundaresan, A. Influence of natural and synthetic antioxidants on the degradation of Soybean oil at frying temperature. J. Food Sci. Technol. 2015, 52, 5370-5375. [CrossRef] [PubMed]

5. Sarkar, A.; Golay, P.; Acquistapace, S.; Craft, B.D. Increasing the oxidative stability of soybean oil through fortification with antioxidants. Int. J. Food Sci. Technol. 2015, 50, 666-673. [CrossRef]

6. Xu, L.; Yu, X.; Li, M.; Chen, J.; Wang, X. Monitoring Oxidative Stability and Changes in Key Volatile Compounds in Edible Oils during Ambient Storage through HS-SPME/GC-MS. Int. J. Food Prop. 2018, 20, S2926-S2938. [CrossRef]

7. Kozłowska, M.; Gruczyńska, E. Comparison of the oxidative stability of soybean and sunflower oils enriched with herbal plant extracts. Chem. Zvesti. 2018, 72, 2607-2615. [CrossRef]

8. Trif, M.; Socaciu, C. Evaluation of effiency, release and oxidation stability of sea buckthorn microencapsulated oil using Fourier transformed infrared spectroscopy. Chem. Listy 2008, 102, 1198-1199.

9. Barden, L.; Vollmer, D.; Johnson, D.; Decker, E. Impact of iron, chelators, and free fatty acids on lipid oxidation in low-moisture crackers. J. Agric. Food Chem. 2015, 63, 1812-1818. [CrossRef]

10. Punia Bangar, S.; Chaudhary, V.; Thakur, N.; Kajla, P.; Kumar, M.; Trif, M. Natural Antimicrobials as Additives for Edible Food Packaging Applications: A Review. Foods 2021, 10, 2282. [CrossRef]

11. Castelo-Branco, V.N.; Santana, I.; Di-Sarli, V.O.; Freitas, S.P.; Torres, A.G. Antioxidant capacity is a surrogate measure of the quality and stability of vegetable oils. Eur. J. Lipid Sci. Technol. 2016, 118, 224-235. [CrossRef]

12. Oliveira, A.S.; Ribeiro-Santos, R.; Ramos, F.; Conceição Castilho, M.; Sanches-Silva, A. UHPLC-DAD multi-method for determination of phenolics in aromatic plants. Food Anal. Methods 2018, 11, 440-450. [CrossRef]

13. Szabo, K.; Dulf, F.V.; Teleky, B.-E.; Eleni, P.; Boukouvalas, C.; Krokida, M.; Kapsalis, N.; Rusu, A.V.; Socol, C.T.; Vodnar, D.C. Evaluation of the Bioactive Compounds Found in Tomato Seed Oil and Tomato Peels Influenced by Industrial Heat Treatments. Foods 2021, 10, 110. [CrossRef]

14. Tannin-Spitz, T.; Bergman, M.; Grossman, S. Cucurbitacin glucosides: Antioxidant and free-radical scavenging activities. Biochem. Biophys. Res. Commun. 2007, 364, 181-186. [CrossRef] [PubMed]

15. Shafaei, H.; Esmaeili, A.; Rad, H.S.; Delazar, A.; Behjati, M. Citrullus colocynthis as a medicinal or poisonous plant: A revised fact. J. Med. Plants Res. 2012, 6, 4922-4927. [CrossRef]

16. Zamuz, S.; Munekata, P.E.; Gullón, B.; Rocchetti, G.; Montesano, D.; Lorenzo, J.M. Citrullus lanatus as source of bioactive components: An up-to-date review. Trends Food Sci. Technol. 2021, 111, 208-222. [CrossRef]

17. Jawad, A.H.; Ngoh, Y.S.; Radzun, K.A. Utilization of watermelon (Citrullus lanatus) rinds as a natural low-cost biosorbent for adsorption of methylene blue: Kinetic, equilibrium and thermodynamic studies. J. Taibah Univ. Sci. 2018, 12, 371-381. [CrossRef]

18. Dietrich, T.; Velasco, M.V.; Echeverría, P.; Pop, B.; Rusu, A. Crop and plant biomass as valuable material for BBB. Alternatives for valorization of green wastes. In Biotransformation of Agricultural Waste and By-Products: The Food, Feed, Fibre, Fuel (4F) Economy; Elsevier: San Diego, CA, USA, 2016.

19. Varnham, A. Seed Oil: Biological Properties, Health Benefits and Commercial Applications; Nova Science Publishers: New York, NY, USA, 2014.

20. Gupta, S.; Kesarla, R.; Omri, A. Formulation Strategies to Improve the Bioavailability of Poorly Absorbed Drugs with Special Emphasis on Self-Emulsifying Systems. Int. Sch. Res. Not. Pharm. 2013, 2013, 848043. [CrossRef]

21. Jurj, A.; Pop, L.A.; Zanoaga, O.; Ciocan-Cârtiţă, C.A.; Cojocneanu, R.; Moldovan, C.; Raduly, L.; Pop-Bica, C.; Trif, M.; Irimie, A.; et al. New Insights in Gene Expression Alteration as Effect of Paclitaxel Drug Resistance in Triple Negative Breast Cancer Cells. Cell Physiol. Biochem. 2020, 54, 648-664. [PubMed] 
22. Corstens, M.N.; Troost, F.J.; Alleleyn, A.M.E.; Klaassen, T.; Berton-Carabin, C.C.; Schroën, K.; Masclee, A.A.M. Encapsulation of lipids as emulsion-alginate beads reduces food intake: A randomized placebo-controlled cross-over human trial in overweight adults. Nutr. Res. 2019, 63, 86-94. [CrossRef] [PubMed]

23. Mohammed, N.K.; Tan, C.P.; Manap, Y.A.; Muhialdin, B.J.; Hussin, A.S.M. Spray Drying for the Encapsulation of Oils-A Review. Molecules 2020, 25, 3873. [CrossRef]

24. Yingngam, B.; Kacha, W.; Rungseevijitprapa, W.; Sudta, P.; Prasitpuriprecha, C.; Brantner, A. Response Surface Optimization of Spray-Dried Citronella Oil Microcapsules with Reduced Volatility and Irritation for Cosmetic Textile Uses. Powder Technol. 2019, 355, 372-385. [CrossRef]

25. Bangar, S.P.; Siroha, A.K.; Nehra, M.; Trif, M.; Ganwal, V.; Kumar, S. Structural and Film-Forming Properties of Millet Starches: A Comparative Study. Coatings 2021, 11, 954. [CrossRef]

26. Bakry, A.M.; Abbas, S.; Ali, B.; Majeed, H.; Abouelwafa, M.Y.; Mousa, A.; Liang, L. Microencapsulation of oils: A comprehensive review of benefits, techniques, and applications. Compr. Rev. Food Sci. Food Saf. 2016, 15, 143-182. [CrossRef]

27. Aluyor, E.O.; Ori-Jesu, M. The use of antioxidants in vegetable oils-A review. Afr. J. Biotechnol. 2008, 7, 4836-4842.

28. Zhang, G.; Chen, Y.; Tariq, K.; An, Z.; Wang, S.; Qumar Memon, F.; Si, H. Optimization of ultrasound assisted extraction method for polyphenols from Desmodium triquetrum (L.) DC. with response surface methodology (RSM) and in vitro determination of its antioxidant properties. Czech J. Food Sci. 2020, 38, 115-122. [CrossRef]

29. Wang, X.; Wu, Y.; Chen, G.; Yue, W.; Liang, Q.; Wu, Q. Optimisation of ultrasound assisted extraction of phenolic compounds from Sparganii rhizoma with response surface methodology. Ultrason. Sonochem. 2013, 20, 846-854. [CrossRef]

30. Mas'ud, F.; Mahendradatta, M.; Laga, A.; Zainal, Z. Optimization of mango seed kernel oil extraction using response surface methodology. OCL 2017, 24, D503. [CrossRef]

31. Rebollo-Hernanz, M.; Cañas, S.; Taladrid, D.; Bartolomé, B.; Aguilera, Y.; Martin-Cabrejas, M.A. Extraction of phenolic compounds from cocoa shell: Modeling using response surface methodology and artificial neural networks. Sep. Purif. Technol. 2021, 270, 118779. [CrossRef]

32. Adesanya, A.O.; Olaseinde, O.O.; Oguntayo, O.D.; Otulana, J.O.; Adefule, A.K. Effects of Methanolic Extract of Citrullus lanatus Seed on Experimentally induced prostatic Hyperplasia. Eur. J. Med. Plants 2011, 1, 171-179.

33. Kolawole, T.; Dapper, D.V.; Oluwatayo, O.B.; Wali, C. Effects of Methanolic Extract of the Rind of Lanatus (Watermelon) in Aspirin Induced Gastric Ulceration in Male Wistar Rats. Merit Res. J. Med. Med Sci. 2016, 4, 344-350.

34. Ștefănescu, B.-E.; Călinoiu, L.F.; Ranga, F.; Fetea, F.; Mocan, A.; Vodnar, D.C.; Crișan, G. Chemical Composition and Biological Activities of the Nord-West Romanian Wild Bilberry (Vaccinium myrtillus L.) and Lingonberry (Vaccinium vitis-idaea L.) Leaves. Antioxidants 2020, 9, 495. [CrossRef] [PubMed]

35. Way, M.L.; Jones, J.E.; Nichols, D.S.; Dambergs, R.G.; Swarts, N.D. A Comparison of Laboratory Analysis Methods for Total Phenolic Content of Cider. Beverages 2020, 6, 55. [CrossRef]

36. Kupina, S.; Fields, C.; Roman, M.C.; Brunelle, S.L. Determination of Total Phenolic Content Using the Folin-C Assay: SingleLaboratory Validation, First Action 2017.13. J. AOAC Int. 2018, 101, 1466-1472. [CrossRef]

37. Refinery, N.P.; Braimah, M.N. Utilization of response surface methodology (RSM) in the optimization of crude oil refinery. J. Multidiscip. Eng. Sci. Technol. 2016, 3, 4361-4369.

38. Gangurde, A.B.; Amin, P.D. Microencapsulation by Spray Drying of Vitamin A Palmitate from Oil to Powder and Its Application in Topical Delivery System. J. Encapsulation Adsorpt. Sci. 2017, 7, 10-39. [CrossRef]

39. Rusu, A.V.; Criste, F.L.; Mierliţă, D.; Socol, C.T.; Trif, M. Formulation of Lipoprotein Microencapsulated Beadlets by Ionic Complexes in Algae-Based Carbohydrates. Coatings 2020, 10, 302. [CrossRef]

40. UTHSCSA. Available online: https://www.uthscsa.edu/academics/dental/departments/comprehensive-dentistry?/dig/itdesc html (accessed on 26 September 2021).

41. Easy Freeware. Available online: https://www.easyfreeware.com/imagetool-191478-freeware.html (accessed on 26 September 2021).

42. Albu, S.; Joyce, E.; Paniwnyk, L.; Lorimer, J.P.; Mason, T.J. Potential for the use of Ultrasound in the Extraction of Antioxidants from Rosmarinus officinalis for the Food and Pharmaceutical Indus. J. Ultrason. Sonochem. 2004, 11, 26. [CrossRef] [PubMed]

43. Rostagno, M.A.; Palma, M.; Barroso, C.G. Ultrasound-assisted extraction of soy is flavones. J. Chromatogr. A 2003, 1012, 119-128. [CrossRef]

44. Ma, Y.; Ye, X.; Hao, Y.; Xu, G.; Xu, G.; Liu, D. Ultrasound assisted extraction of hesperidin from Penggan (Citrus reticulata) peel. Ultrason. Sonochem. 2008, 15, 227-232. [CrossRef]

45. Zou, T.-B.; Wang, M.; Gan, R.-Y.; Ling, W.-H. Optimization of Ultrasound-Assisted Extraction of Anthocyanins from Mulberry, Using Response Surface Methodology. Int. J. Mol. Sci. 2011, 12, 3006-3017. [CrossRef] [PubMed]

46. Kamran Khan, M.; Abert-Vian, M.; Fabiano-Tixier, A.S.; Dangles, O.; Chemat, F. Ultrasound-assisted extraction of polyphenols (flavanone glycosides) from orange (Citrus sinensis L.) peel. Food Chem. 2010, 119, 851-858. [CrossRef]

47. Wang, J.; Sun, B.; Cao, Y.; Tian, Y.; Li, X. Optimization of ultrasound assisted extraction of phenolic compounds from wheat bran. Food Chem. 2008, 106, 804-810. [CrossRef]

48. Gao, W.; Wang, Y.Q.; Basavanagoud, B.; Jamil, M.K. Characteristics studies of molecular structures in drugs. Saudi Pharm. J. 2017, 25, 580-586. [CrossRef] 
49. Qadir, R.; Anwar, F.; Gilani, M.A.; Zahoor, S.; Misbah ur Rehman, M.; Mustaqeem, M. RSM/ANN based optimized recovery of phenolics from mulberry leaves by enzyme-assisted extraction. Czech J. Food Sci. 2019, 37, 99-105. [CrossRef]

50. Weremfo, A.; Adulley, F.; Adarkwah-Yiadom, M. Simultaneous Optimization of Microwave-Assisted Extraction of Phenolic Compounds and Antioxidant Activity of Avocado (Persea americana Mill.) Seeds Using Response Surface Methodology. J. Anal. Methods Chem. 2020, 2020, 7541927. [CrossRef]

51. Vinatoru, M.; Mason, T.J.; Calinescu, I. Ultrasonically assisted extraction (UAE) and microwave assisted extraction (MAE) of functional compounds from plant materials. TrAC Trends Anal. Chem. 2017, 97, 159-178. [CrossRef]

52. Monzón, L.; Becerra, G.; Aguirre, E.; Rodríguez, G.; Villanueva, E. Ultrasound-assisted extraction of polyphenols from avocado residues: Modeling and optimization using response surface methodology and artificial neural networks. Sci. Agropecu. 2021, 12, 33-40. [CrossRef]

53. Chávez-González, M.L.; Sepúlveda, L.; Verma, D.K.; Luna-García, H.A.; Rodríguez-Durán, L.V.; Ilina, A.; Aguilar, C.N. Conventional and Emerging Extraction Processes of Flavonoids. Processes 2020, 8, 434. [CrossRef]

54. Kv, S.; Thejasri Br, K.; Gds, S.; Sivaji, G. Optimization of ultrasound-assisted extraction of watermelon seed oil using response surface methodology. Pharma Innov. J. 2018, 7, 546-549.

55. Bimakr, M.; Rahman, R.A.; Taip, F.S.; Adzahan, N.M.; Sarker, M.Z.I.; Ganjloo, A. Optimization of Ultrasound-Assisted Extraction of Crude Oil from Winter Melon (Benincasa hispida) Seed Using Response Surface Methodology and Evaluation of Its Antioxidant Activity, Total Phenolic Content and Fatty Acid Composition. Molecules 2012, 17, 11748-11762. [CrossRef]

56. Fadimu, G.J.; Ghafoor, K.; Babiker, E.E.; Fahad, A.J.; Abdulraheem, R.A.; Adenekan, M.K. Ultrasound-assisted process for optimal recovery of phenolic compounds from watermelon (Citrullus lanatus) seed and peel. Food Meas. 2020, 14, 1784-1793. [CrossRef]

57. Özbek, Z.A.; Günç Ergönül, P. Chapter 51—Cold pressed soybean oil. In Cold Pressed Oils; Ramadan, M.F., Ed.; Academic Press: Cambridge, MA, USA, 2020; pp. 575-585. ISBN 9780128181881.

58. Trif, M.; Vodnar, D.C.; Mitrea, L.; Rusu, A.V.; Socol, C.T. Design and Development of Oleoresins Rich in Carotenoids Coated Microbeads. Coatings 2019, 9, 235. [CrossRef]

59. Lim, H.W.; Jang, H.M.; Ha, S.M.; Chai, Y.G.; Yoo, S.I.; Zhang, B.T. A Lab-on-a-Chip Module for Bead Separation in DNABased Concept Learning. In DNA Computing. DNA 2003. Lecture Notes in Computer Science; Chen, J., Reif, J., Eds.; Springer: Berlin/Heidelberg, Germany, 2004; Volume 2943.

60. Ruger, C.W.; Klinker, E.J.; Hammond, E.G. Abilities of Some Antioxidants to Stabilize Soybean Oil in Industrial use Conditions. J. Am. Oil Chem. Soc. 2002, 79, 733-736. [CrossRef]

61. Yang, C.Y.; Mandal, P.K.; Han, K.H.; Fukushima, M.; Choi, K.; Kim, C.J.; Lee, C.H. Capsaicin and tocopherol in red pepper seed oil enhances the thermal oxidative stability during frying. J. Food Sci. Technol. 2010, 47, 162-165. [CrossRef] [PubMed]

62. Taghvaei, M.; Jafari, S.M.; Sadeghi-Mahoonak, A.; Mehregan-Nikoo, A.; Rahmanian, N.; Hajitabar, J.; Meshginfar, N. The effect of natural antioxidants extracted from plant and animal resources on the oxidative stability of soybean oil. LWT Food Sci. Technol. 2014, 56, 124-130. [CrossRef]

63. Suja, K.P.; Abraham, J.T.; Thamizh, S.N.; Jayalekshmy, A.; Arumughan, C. Antioxidant efficacy of sesame cake extract in vegetable oil protection. Food Chem. 2004, 84, 393-400. [CrossRef]

64. Taghvaei, M.; Jafari, S.M. Application and stability of natural antioxidants in edible oils in order to substitute synthetic additives. J. Food Sci. Technol. 2015, 52, 1272-1282. [CrossRef] [PubMed]

65. Trif, M.; Csutak, E.; Perez-Moral, N.; Gagyi, T.; Pintori, D.; Bethke, M.; Wilde, P.J. Terifiq Eu Project: Multiple Gel in Oil in Water Emulsions as Fat Replacers in Sauces and Ready Prepared Foods. Bull. Univ. Agric. Sci. Veter-Med. Cluj-Napoca. Food Sci. Technol. 2016, 73, 47-48. [CrossRef]

66. Bangar, S.P.; Purewal, S.S.; Trif, M.; Maqsood, S.; Kumar, M.; Manjunatha, V.; Rusu, A.V. Functionality and Applicability of Starch-Based Films: An Eco-Friendly Approach. Foods 2021, 10, 2181. [CrossRef] [PubMed]

67. Hannachi, H.; Benmoussa, H.; Saadaoui, E.; Saanoun, I.; Negri, N.; Elfalleh, W. Optimization of ultrasound and microwaveassisted extraction of phenolic compounds from olive leaves by response surface methodology. Res. J. Biotechnol. 2019, 14, 28-37.

68. Pan, G.Y.; Yu, G.Y.; Zhu, C.H.; Qiao, J.L. Optimization of ultrasound-assisted extraction (UAE) of flavonoids compounds (FC) from hawthorn seed (HS). Ultrason. Sonochem. 2012, 19, 486-490. [CrossRef] [PubMed]

69. Dobrinčić, A.; Repajić, M.; Garofulić, I.E.; Tuđen, L.; Dragović-Uzelac, V.; Levaj, B. Comparison of Different Extraction Methods for the Recovery of Olive Leaves Polyphenols. Processes 2020, 8, 1008. [CrossRef]

70. Yao, Y.; Pan, Y.; Liu, S. Power ultrasound and its applications: A state-of-the-art review. Ultrason. Sonochem. 2020, 62, 104722. [CrossRef]

71. Mitrea, L.; Ranga, F.; Fetea, F.; Dulf, F.V.; Rusu, A.; Trif, M.; Vodnar, D.C. Biodiesel-Derived Glycerol Obtained from Renewable Biomass-A Suitable Substrate for the Growth of Candida zeylanoides Yeast Strain ATCC 20367. Microorganisms $2019,7,265$. [CrossRef] [PubMed]

72. Fäldt, P.; Bergenståhl, B. Spray-dried whey protein/lactose/soybean oil emulsions. 1. Surface composition and particle structure. Food Hydrocoll. 1996, 10, 421-429. [CrossRef]

73. Maurer, S.; Ghebremedhin, M.; Zielbauer, B.I.; Knorr, D.; Vilgis, T.A. Microencapsulation of soybean oil by spray drying using oleosomes. J. Phys. D Appl. Phys. 2016, 49, 054001. [CrossRef] 
74. Mori, C.; Kadota, K.; Tozuka, Y.; Shimosaka, A.; Yoshida, M.; Shirakawa, Y. Application of nozzleless electrostatic atomization to encapsulate soybean oil with solid substances. J. Food Eng. 2019, 246, 25-32. [CrossRef]

75. Cimino, R.; Bhangu, S.K.; Baral, A.; Ashokkumar, M.; Cavalieri, F. Ultrasound-Assisted Microencapsulation of Soybean Oil and Vitamin D Using Bare Glycogen Nanoparticles. Molecules 2021, 26, 5157. [CrossRef] [PubMed]

76. Priyanka, S.S.; Chetan, B.P.; Pramod, P.M. Preparation and Characterization of Microcapsules Containing Soybean Oil and Their Application in Self-Healing Anticorrosive Coatings. Polym. Plast. Technol. Eng. 2008, 57, 1334-1343.

77. Ding, J.; Xu, Z.; Qi, B.; Cui, S.; Wang, T.; Jiang, L.; Zhang, Y.; Sui, X. Fabrication and characterization of soybean oil bodies encapsulated in maltodextrin and chitosan-EGCG conjugates: An in vitro digestibility study. Food Hydrocoll. $2019,94,519-527$. [CrossRef]

78. Chen, B.; McClements, D.J.; Gray, D.A.; Decker, E.A. Stabilization of soybean oil bodies by enzyme (laccase) cross-linking of adsorbed beet pectin coatings. J. Agric. Food Chem. 2010, 58, 9259-9265. [CrossRef] [PubMed]

79. Wu, N.; Huang, X.; Yang, X.; Guo, J.; Yin, S.; He, X.; Wang, L.-J.; Zhu, J.-H.; Qi, J.-R.; Zheng, E.-L. In vitro assessment of the bioaccessibility of fatty acids and tocopherol from soybean oil body emulsions stabilized with t-carrageenan. J. Agric. Food Chem. 2012, 60, 1567-1575. [CrossRef] [PubMed]

80. Wu, N.; Huang, X.; Yang, X.; Guo, J.; Zheng, E.; Yin, S.; Zhu, J.-H.; Qi, J.-R.; He, X.-T.; Zhang, J.-B. Stabilization of soybean oil body emulsions using l-carrageenan: Effects of salt, thermal treatment and freeze-thaw cycling. Food Hydrocoll. 2012, 28, 110-120. [CrossRef]

81. Wu, N.; Yang, X.; Teng, Z.; Yin, S.; Zhu, J.; Qi, J. Stabilization of soybean oil body emulsions using $\kappa, \mathrm{l}, \lambda$-carrageenan at different pH values. Food Res. Int. 2011, 44, 1059-1068. [CrossRef]

82. Liu, C.; Wang, R.; He, S.; Cheng, C.; Ma, Y. The stability and gastro-intestinal digestion of curcumin emulsion stabilized with soybean oil bodies. LWT Food Sci. Technol. 2020, 131, 109663. [CrossRef]

83. Mitrea, L.; Călinoiu, L.F.; Precup, G.; Bindea, M.; Rusu, B.; Trif, M.; Ferenczi, L.J.; Ștefănescu, B.E.; Vodnar, D.C. Inhibitory potential of Lactobacillus plantarum on Escherichia coli. Bull. UASVM Food Sci. Technol. 2017, 74, 99-101. [CrossRef]

84. Hao, J.; Xu, D.; Cao, Y. Recent developments and prospects in the composition, extraction, stability, delivery system, digestion and food applications of plant oil bodies. Authorea 2021. [CrossRef] 